\title{
1997 Award in honor of Fred L. Soper (1893-1976) for publications in the field of Inter-American Health*
}

This is an announcement and call for submission of nominations for the 1997 award in honor of Fred. L. Soper, former Director of the Pan American Health Organization (the World Health Organization Regional Office for the Americas) from 1947 to 1958.

In addition to his service with PAHO/WHO, Dr. Soper played a major role in the fight against yellow fever and other infectious diseases in Brazil as part of his work with the Rockefeller Foundation in the 1920s and 1930s and in the control of typhus in North Africa and Italy during the Second World War. He was one of the truly major figures of the century in inter-American health.

The Award is presented annually to the author or authors of an original scientific contribution comprising new information on, or new insights into, the broad field of public health, with special relevance to Latin America or the Caribbean or both. This may consist of a report, an analysis of new data, experimental or observational, or a new approach to analysing available data. Preferences is given to studies involving more than one discipline and to papers related to infectious disease, a life-long concern of Dr. Soper.

Only papers already published is scientific journals listed in the Index Medicus or in the official journals of the Pan American Health Organization are eligible for consideration. Furthermore, the Award is limited to contributions by authors whose principal affiliation is with teaching, research or service institutions located in the countries of Latin America and the Caribbean (including the Centers of the Pan American Health Organization).

The Award Fund is administered by the Pan American Health and Education Foundation (PAHEF), which receives voluntary contributions designated for the purpose and holds them is a separate fund. The Award consists of a suitable certificate and a monetary prize od US4 1000,00. The winner(s) of the Award each year is nominated by an Award Committee, composed of representatives designated by PAHO and by PAHEF; final selection is made by the Board of Trustees of PAHEF.

Papers submitted by or on behalf of their authors may be considered for the Fred L. Soper Award. For purposes of the 1997 Award, only papers published during calendar year 1996 will be considered; all submissions must be received by 31 March 1997 at the following address:

\section{Executive Secretary \\ PAHEF \\ 52523 rd Street N. W. \\ Washington, DC 20037 \\ USA}

